\title{
LA PRESENCIA BOLIVIANA EN EL DESIERTO DE ATACAMA DESPUÉS DE LA POSTGUERRA DE 1879. PATRONES DE MIGRACIÓN E INSERCIÓN EN LA SOCIEDAD DE ANTOFAGASTA*
}

\author{
BOLIVIAN PRESENCE IN THE ATACAMA DESERT AFTER THE WAR OF 1879. \\ POSTWAR MIGRATION PATTERNS AND INTEGRATION INTO ANTOFAGASTA'S \\ SOCIETY
}

\author{
José Antonio González Pizarro**, Marcelo Lufin Varas ${ }^{* * *}$ y Claudio Galeno Ibaceta****
}

\begin{abstract}
El trabajo se centra en el análisis de los flujos demográficos desde Bolivia hacia la ciudad de Antofagasta, durante el apogeo del ciclo del nitrato, entre 1880 y 1930. Para ello, en base del archivo histórico del Registro Civil e Identificaciones, se estudian los prontuarios personales del contingente boliviano que se radicó en la capital de la provincia de Antofagasta.

Se examina la situación de Bolivia para apreciar los factores que posibilitaron tal migración desde las distintas áreas geográficas y, de igual modo, las condiciones que exhibía la ciudad de Antofagasta en el periodo.

El análisis de los documentos permite diferenciar los aportes de cada departamento de Bolivia, el género, la edad, su capital social y las etapas en que se verificaron tales flujos y determinar que los bolivianos establecidos en Antofagasta fueron mayoritariamente de ascendencia española u europea.
\end{abstract}

Palabras claves: Bolivianos, Antofagasta, salitre, migración, sociedad.

This paper focuses on the analysis of the demographic flows from Bolivia to the city of Antofagasta during the apogee of the nitrate cycle between 1880 and 1930. So, the personal records of the Bolivian contingent establishing in the capital city of Antofagasta province are studied, based on historical files of the Civil Registration Office.

The Bolivian situation is studied in order to appreciate the factors that made migration possible from various geographic areas, along with the conditions of Antofagasta city during that period.

The analysis of documents allows differentiating the contributions of each Bolivian department, gender, age, social capital, and the periods in which these flows occurred, together with determining that Bolivians establishing in Antofagasta were mainly Spanish or European descendants.

Key words: Bolivians, Antofagasta, nitrate, migration, society.

\section{Introducción}

El trabajo que se presenta forma parte de un análisis mayor acerca de la población boliviana que se trasladó desde sus provincias originarias a establecerse en la región de Antofagasta principalmente durante el apogeo de la era del nitrato, entre 1880 y 1930 . Un gran porcentaje se localizó en la depresión intermedia donde se había levantado la poderosa industria salitrera, esparcida en cuatro cantones principales, siendo el denominado Cantón Central, que une a la ciudad de Antofagasta en línea recta con el poblado de Sierra Gorda, el que concentró la mayor cantidad de instalaciones industriales y campamentos. No obstante, las ciudades, principalmente Antofagasta, también atrajeron a un significativo número de inmigrantes bolivianos y, en menor medida, los poblados precordilleranos próximos a Calama.

Sobre la base del rico archivo histórico de extranjería del Registro Civil e Identificación, de la Universidad Católica del Norte, que reúne miles de prontuarios bolivianos en toda la región, deseamos exponer los rasgos de esta población migrante de Bolivia en la ciudad de Antofagasta, a base de las siguientes variables: a) Orígenes geográficos de la migración y distribución de género; b) Capital social del migrante y etapas temporales de la inmigración, c) Grupos etarios que compusieron el proceso de migración, d) La composición étnica y e) Patrones de nupcialidad.

\footnotetext{
* Resultado proyecto FONDECYT No 1130785, año 2014.

** Universidad Católica del Norte. Facultad de Ciencias Jurídicas. Centro de Estudios Histórico-Jurídicos. Antofagasta, Chile. Correo electrónico: jagonzal@ucn.cl

*** Universidad Católica del Norte, Facultad de Economía y Administración, Departamento de Economía. Antofagasta, Chile. Correo electrónico: mlufin@ucn.cl

**** Universidad Católica del Norte, Escuela de Arquitectura. Antofagasta, Chile. Correo electrónico: cgaleno@ucn.cl
} 
Para el estudio del caso de la ciudad de Antofagasta examinaremos 707 casos de ciudadanos bolivianos comprendidos en los prontuarios de filiación entre 1901 y 1930, que declaran como localización de residencia direcciones de sectores históricos en relación con el plano fundacional.

\section{El contexto histórico binacional durante los ciclos mineros del salitre y de la plata/estaño}

La presencia boliviana en el desierto de Atacama durante el ciclo salitrero obedeció por una parte a la continuidad de esta en los poblados de los faldeos cordilleranos, que va a constituir en 1925 el departamento del Loa, con capital Calama. Habrá que señalar que el flujo boliviano fue demográficamente muy exiguo en comparación con la habida tanto en la pampa salitrera como también en la que se diseminó en las ciudades costeras, principalmente Antofagasta.

La población boliviana en el litoral siempre fue escasa comparada con otros segmentos demográficos presentes en Antofagasta. Así lo revela el censo de 1875 y más tarde el levantado en 1878 , ambos por el municipio antofagastino (Rojas, 2012 [1883]: 277; Bermúdez, 1963: 371).

No obstante, el largo periodo de postguerra hasta el tratado de 1904 posibilitó un acercamiento de los intereses comerciales de ambas naciones, simbolizado en la Compañía Huanchaca de Bolivia, que conjugó en la década de 1880 el monopolio del agua para la ciudad y a la vez el nexo entre las minas de plata de Pulacayo cercana a Potosí en Bolivia y el complejo metalúrgico de Huanchaca, en el sector meridional de Antofagasta, que funcionó entre 1890-1902 y en la unión del ferrocarril desde Antofagasta hasta Oruro, en 1892 (Ahumada, 1985; Blakemore, 1996: 58). Un periodo de grandes contrastes regionales en Bolivia, mientras la modernización avanzaba con el presidente Arce, mediante el ferrocarril y nuevas conexiones hacia el interior, afianzando el eje minero Oruro-Potosí, la región del oriente y de las zonas agrarias no se desenvolvieron por el obstáculo que significó la gran propiedad agraria, el latifundio (Mesa, Gisbert, 1998: 475-485). La articulación regional comprendió determinados departamentos como La Paz, Cochabamba, Oruro y Potosí y, como puntualiza Márquez Ostria, "con sus hinterlands mineros o agropecuarios en torno al conjunto de relaciones de producción, mercancías y recursos financiero-comerciales" (Márquez, 2003: 41).
A las tensiones indígenas en la región oriental se verificó la masacre de los chiriguanos en 1892 y más tarde a los grandes levantamientos como el de Jesús de Machaca, en 1921, y el de Chayanta, en 1927, se sucedieron las que sacudieron al movimiento obrero, como la masacre de Uncía en 1923 y las organizaciones sindicales en la década de 1920 y la irrupción del discurso anarquista junto al ideario socialista (Rodríguez Leyton, 2007; Lora, 1969).

Sin embargo, la riqueza de la plata desapareció de Bolivia y como afirma Roberto Querejazu, el siglo XX encontró a Bolivia renovada en riqueza -el estaño- y en gobernantes (Querejazu, 2004: 539), aunque la industria extractiva llevaría a la nación en la segunda década del siglo a una aguda crisis económica que afectó notablemente al pueblo y a un cuestionamiento a la autoridad política por el manejo de las relaciones internacionales con Brasil y Chile (Valencia, 1982: 463; Carvalho, 2010: 149-154).

Tanto la asimetría de las regiones bolivianas y la cercanía de otras con la frontera incidieron en la toma de decisión de emigrar.

Oruro se mostraba como la urbe más pujante y la colonia chilena -y sus inversiones- era la comunidad latinoamericana más importante presente en las grandes empresas mineras. La importante ciudad minera de Bolivia exhibía un empuje modernizador llevado a cabo por su elite y por el aporte extraordinario de la presencia europea (Mendieta 2006: 205-231; Iño Daza, 2008). Constituyó un destino de las comunicaciones entre Chile y Bolivia, lo que motivó además el decidido interés de la provincia de Tarapacá de conectarse con esta industriosa ciudad boliviana (González Miranda, 2011).

Las posibilidades que ofrecía el norte chileno en la época eran considerables. Chile vivía una política liberal en su economía, la que había abierto las cuantiosas inversiones en la industria salitrera y en la cuprera Chuquicamata en la segunda mitad del siglo XX -percibiendo impuestos de esta que invertía en infraestructura-; y en el caso de Antofagasta, se planifica a partir de 1905 levantar un molo fiscal en reemplazo de los muelles históricos provenientes de las décadas de 1870-1880. Había una visión de absoluta libertad de tránsito en sus fronteras, que las guías de viajeros enfatizaban en la no necesidad de pasaportes (Manual, 1910: 35).

Las relaciones diplomáticas con Bolivia se observaban en el plano de las esferas estatales no afectando la vida cotidiana, principalmente en el norte donde los intercambios comerciales entre ambos 
países se evidenciaban notablemente, donde casas comerciales europeas asentadas en la ciudad, como ser Gildemeister \& Co, Casa Gibbs \& Co., tenían fluidos nexos mercantiles con ciudades bolivianas como Oruro o La Paz, o bien establecimientos industriales nacionales, la Fundición y Fábrica Orchard, Fábrica de Tejidos de Punto de Marull y Co. Ltd., Hotel Londres, Sociedad Comercial Sabioncello, el Hotel Milano, estimado "el preferido por los pasajeros en tránsito a Bolivia", o la Sastrería Inglesa, cuyo dueño era boliviano, o el Agente de Aduanas Jorge Larrieu, cuya oficina central estaba en La $\mathrm{Paz}$, eran expresiones de los estrechos vínculos entre el norte chileno y las principales ciudades de Bolivia, como lo consignó la publicación oficial del centenario de la independencia de Bolivia (Alarcón, 1925: 36-39;550-572).

Hacia 1910 ambos países habían asumido sus respectivas crisis nacionales. En Chile, la denominada crisis moral de MacIver y la cuestión social erigida con fuerza por Luis Emilio Recabarren; en Bolivia, la cuestión palpitante era la denominada cuestión indígena y la instrucción (González Pizarro, 2007, 2009).

\section{La ciudad de Antofagasta y la colonia boliviana}

Si nos aproximamos a las bondades que exhibía la ciudad de Antofagasta en el periodo, es factible mencionar algunos hitos importantes. La superación del impacto de las leyes salitreras que gravaban los cantones de Taltal, Aguas Blancas y Central, en la década de 1880, a favor de la poderosa industria calichera de Tarapacá, mediante las instalaciones de la Compañía Huanchaca en Antofagasta y la formación de la Población Playa Blanca, en 1889; la habilitación del puerto de Coloso en 1905 para dar salida a la producción salitrera de las oficinas del cantón de Aguas Blancas; el impacto de la red ferroviaria de la Empresa de Ferrocarriles de Antofagasta a Bolivia, en 1892 y su ampliación a partir de 1904, y el establecimiento de la Maestranza de Mejillones en 1906, que significó la refundación del poblado (Panadés-González, 1998). A estos hechos habría que adicionar la gran bonanza salitrera de 1907 que, al decir de Silva Lezaeta (González-Hubert, 2013), provocó un resurgimiento de la pampa y de la actividad comercial y portuaria de Antofagasta. En este contexto, se puede graficar el enorme impacto de la industria salitrera en el erario fiscal chileno (Couyoumdjian,
1986). Habrá que señalar que las ofertas de mercado eran amplias, vinculadas de una u otra forma con el hinterland salitrero. Estas constituían un espectro que abarcaba desde las demandas de empleados en múltiples locales y almacenes de abarrotes, en trabajos especializados de contabilidad y secretariado de las grandes casas comerciales europeas.

Además, estaban los múltiples trabajos que exigían los avances de infraestructura básica de la ciudad. La red de agua potable y de agua salada se fue desarrollando desde 1892, como lo muestra un plano depositado en el Archivo del FCAB firmado por el ingeniero británico R. J. Manning. El alcantarillado se fue construyendo desde 1905 y se amplió en 1916. La pavimentación se inició en 1915.

Asimismo, los operarios vinculados con la construcción que va cubriendo los espacios incorporados a la demarcación urbana, en la constitución de barrios residenciales en torno a la Avenida del Brasil, o en la expansión del sector sur-oriental que devino con la construcción del gran Hospital del Salvador entre 1906 y 1913 y el avance desde calle Díaz Gana hacia el Club Hípico para la hijuelación de la Población Obrera La Favorecedora hacia la década del treinta. Lo mismo acontece con el sector septentrional que en la orientación nordeste se ve coronado con las construcciones tanto del acceso del Cementerio General en 1910 como de la Escuela Huanchaca, las cocheras de FCAB y la Nueva Estación Ferroviaria en calle Valdivia. Punta de lanza para la planificación de las Poblaciones Obreras de Matta y el ensanche de la Población Oriente.

La misma provincia había experimentado un explosivo aumento demográfico, de acuerdo con los censos nacionales (Tabla 1):

Tabla 1. Crecimiento de la población en la provincia de Antofagasta: 1885-1930

\begin{tabular}{ccccc}
\hline 1885 & 1895 & 1907 & 1920 & 1930 \\
\hline 33.636 & 44.085 & 113.323 & 172.330 & 178.765 \\
\hline
\end{tabular}

Fuente: Dirección 1930, Vol. I, p. 40.

Guarismos que recogían la gravitación de la industria salitrera y el encadenamiento económico desencadenado en la capital de la provincia, principalmente en el periodo de mayor auge de la actividad calichera, entre 1895 y 1907, como lo revela la intensidad de crecimiento del desarrollo de la población (Tabla 2): 
Tabla 2. Intensidad del desarrollo de la población: $\%$ aumento o disminución anual

\begin{tabular}{ccc}
\hline $1895-1907$ & $1907-1920$ & $1920-1930$ \\
\hline 73,0 & 35,5 & 3,9 \\
\hline
\end{tabular}

Fuente: Dirección 1930, Vol. I, p. 47.

La gran concentración de población urbana -98,2\% en el censo de 1930- hizo que la ciudad de Antofagasta mostrara una expansión demográfica que dobla el porcentaje del censo precedente, principalmente visible si comparamos los censos de 1907 y 1920 (Tabla 3):

Tabla 3. Población del departamento y de la ciudad de Antofagasta: 1885-1930

\begin{tabular}{lccccc}
\hline \multicolumn{1}{c}{ Censos } & 1885 & 1895 & 1907 & 1920 & 1930 \\
\hline Departamento & 12.566 & 16.617 & 60.447 & 101.604 & 89.998 \\
Ciudad & 7.588 & 13.530 & 32.496 & 51.531 & 53.591 \\
\hline
\end{tabular}

Fuente: Dirección 1930, Vol.I, pp. 41 y 46.

Destaquemos que hacia el final del ciclo salitrero la ciudad de Antofagasta exhibía una distribución de la población activa, en ramas de la actividad económica, que mostraba el predominio de la incidencia del hinterland minero en el casco urbano, donde la actividad minera concentraba el $44 \%$, seguido por la navegación con $19,6 \%$, más distante comunicaciones con $9,8 \%$, comercio con $4,6 \%$, administración $5,2 \%$, industria 3, $0 \%$, defensa nacional $3,6 \%$, profesiones liberales $2,5 \%$, servicio doméstico $1,5 \%$, agua y pesca $0,3 \%$ y otros con 2,0 (Dirección 1930, Vol. III: XI).

Si nos acercamos a la población boliviana, la mayor presencia acontece en 1907: ese año marcó el cenit de los extranjeros en Chile con 4, $2 \%$ del total, es decir, 134.524 habitantes eran extranjeros, de ellos $16 \%$ eran bolivianos -o sea, 21.968- a nivel nacional, mientras Antofagasta registra $19,5 \%$ de extranjeros, casi cinco veces más que la media nacional, de estos $40 \%$ eran bolivianos, 5.828 personas. En 1920 la reducción de extranjeros es drástica, demostrado en el 3\% del total nacional. En 1930 la población boliviana -a nivel nacional-quedó reducida a la mitad de 1920. En Antofagasta, en 1930 se registraron 5.315 bolivianos.

Los flujos migratorios bolivianos quedaron determinados por diversas variables, considerando que el espacio geográfico de Antofagasta le era afín, sea por vincularse mediante relaciones étnicas o sociales de compadrazgo en los faldeos cordilleranos, donde empleó con bastante regularidad las redes sociales, logrando determinadas familias relevantes en la sociedad y la historia boliviana, como los descendientes de Eduardo Abaroa y de Irene Rivero, abrirse hacia las relaciones sociales en Antofagasta, como aconteció con su hijo Eugenio Abaroa Rivero, que finalmente se relacionó con la familia croata de los Luksic (González Pizarro, 2008). Dentro de esta comunidad, que mantiene comunicación con sus localidades de origen y conexión al interior de la región de Antofagasta, se pudo plantear, en aquellos capacitados en su formación profesional o en oficios especializados, decisiones económicas de carácter individual o que afectaban a sus grupos familiares: la perspectiva del salario esperado y no el percibido (Todaro 1969) como decisión para emigrar desde sus localidades originarias hacia ciudades que brindaban amplias posibilidades de trabajo y remuneraciones en un mercado laboral amplio, como era Antofagasta. En otras circunstancias, consideró las "pautas socioculturales" que refiere Alfred Schutz (Schutz, 1974) o las justipreciaciones de percepciones y conocimientos a los lugares de destino y los obstáculos intervinientes, como se ha observado en los flujos de bolivianos hacia los asientos salitreros y de Chuquicamata, en el mismo periodo (González Pizarro, 2010).

La ciudad de Antofagasta se constituyó como una urbe cosmopolita, abierta a la inmigración, donde su espacio urbano albergó simultáneamente áreas residenciales y comerciales con determinadas edificaciones destinadas a cité o conventillo, que fue una proyección de la especulación inmobiliaria que afectó al crecimiento económico, al desarrollo arquitectónico, a la expansión de los establecimientos educacionales y por cierto a la creciente necesidad de nuevas viviendas para una población que se aventuraba al riesgo o al albur de la fortuna personal atraído por el magnetismo de una pujante actividad industrial y comercial.

Un testimonio boliviano de 1925 , asevera de la ciudad:

Sus calles ricamente pavimentadas, recorridas incesantemente por vehículos modernos, su comercio activísimo, sus lindos almacenes y edificios y la animación que se siente en 
todas partes, le dan un atractivo especial y fisonomía de ciudad moderna y progresista. Hay agencias de los principales bancos americanos y europeos, casinos, hoteles, quintas de recreo, teatro y diversiones y cuanto alegra y facilita la vida. El tren que se dirige a Bolivia... ofrece todas las comodidades precisas para el viaje, en el que hay que pernoctar en los vagones y comer y almorzar en ellos (Alarcón 1925: 33-35).
Hubo una correlación entre el capital social y la localización residencial, esto se puede apreciar en ciertas calles comerciales, como Bolívar, Baquedano, Sucre o Matta o el encuentro de ellas como Bolívar con Latorre, Matta con Baquedano, Matta con Bolívar o Latorre con Maipú. Una imagen de la ubicación de los bolivianos en la ciudad refrenda la preferencia en el área céntrica de la urbe, como se aprecia en la Figura 1.

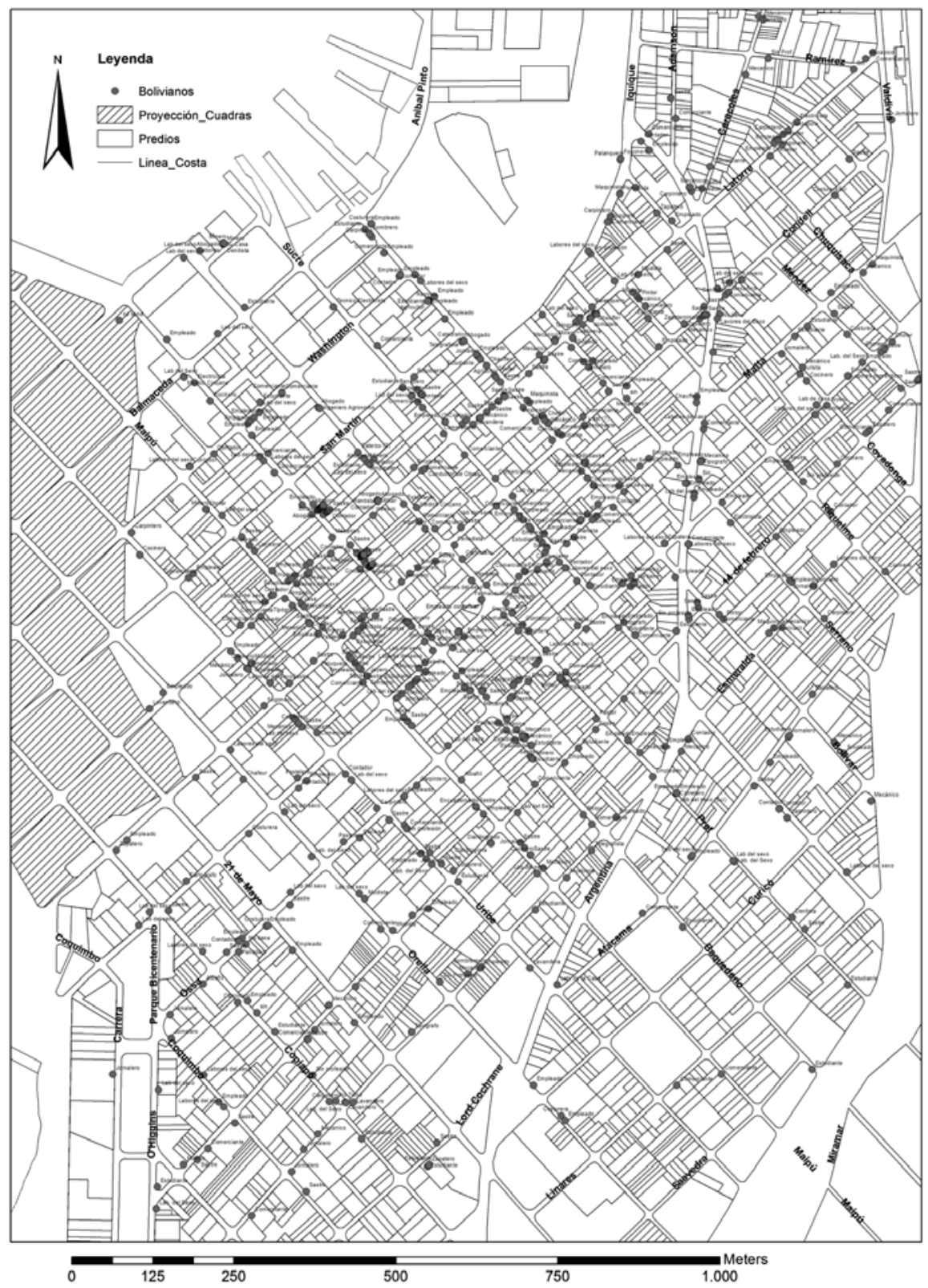

Figura 1. Bolivianos emplazados en el centro de la ciudad, con indicación de profesiones.

Fuente: Elaboración propia. 
De los dieciséis abogados bolivianos registrados, por ejemplo, Luis Lobo Flores, proveniente de Sucre, casado, que llegó en 1920, fijó como domicilio el Hotel Buenos Aires (AHE, 59: P. 13414) ${ }^{1}$, mientras el paceño Julio Guzmán Molina, casado que arribó el mismo año, fijó su domicilio en calle Bolívar 541 (AHE, 56: P. 13044). El farmacéutico Zenón Gamboa Antezana, cochabambino, soltero, desde 1923, fijó su residencia en el Hotel Español (AHE, 54:P. 104121).

Por lo general, en todos los grupos de inmigrantes que hemos estudiado, los que poseyeron un título profesional o un oficio calificado de reconocimiento social, de modo indistinto, si estuviesen en un hotel o una casa habitación, se localizaron en el centro de la urbe, próximos a la Plaza Colón, referente social y comercial de la urbe, símbolo de los poderes políticos y eclesiásticos. En el caso de los bolivianos, si vemos los planos de geolocalización, veremos que la mayoría se mantuvo en torno al centro de la ciudad, independiente de su profesión (Figura 2).

El estatus del capital social radicó en tres factores graduales: a) su condición respecto de su alfabetización, aunque hubo excepciones donde una persona, comerciante, era analfabeto, pero ejerció su oficio, posiblemente auxiliado por su mujer, como fue el caso de Agustín Huara Mamani, un paceño que llegó en 1910 (AHE, 57:P. 9515). La mayoría declara saber leer y escribir, en los segmentos de comerciantes y sastres radicados en Antofagasta. Otros factores fueron: b) la experiencia del oficio y las relaciones y c) la certificación de sus estudios profesionales.

El sociólogo Richard Sennett, respecto de la economía, la industria y la localización de la ciudad del siglo XIX, ha identificado el taller como el espacio productivo que se mantenía en el centro de los asentamientos: "El comercio, las finanzas y la burocracia seguían siendo las principales actividades

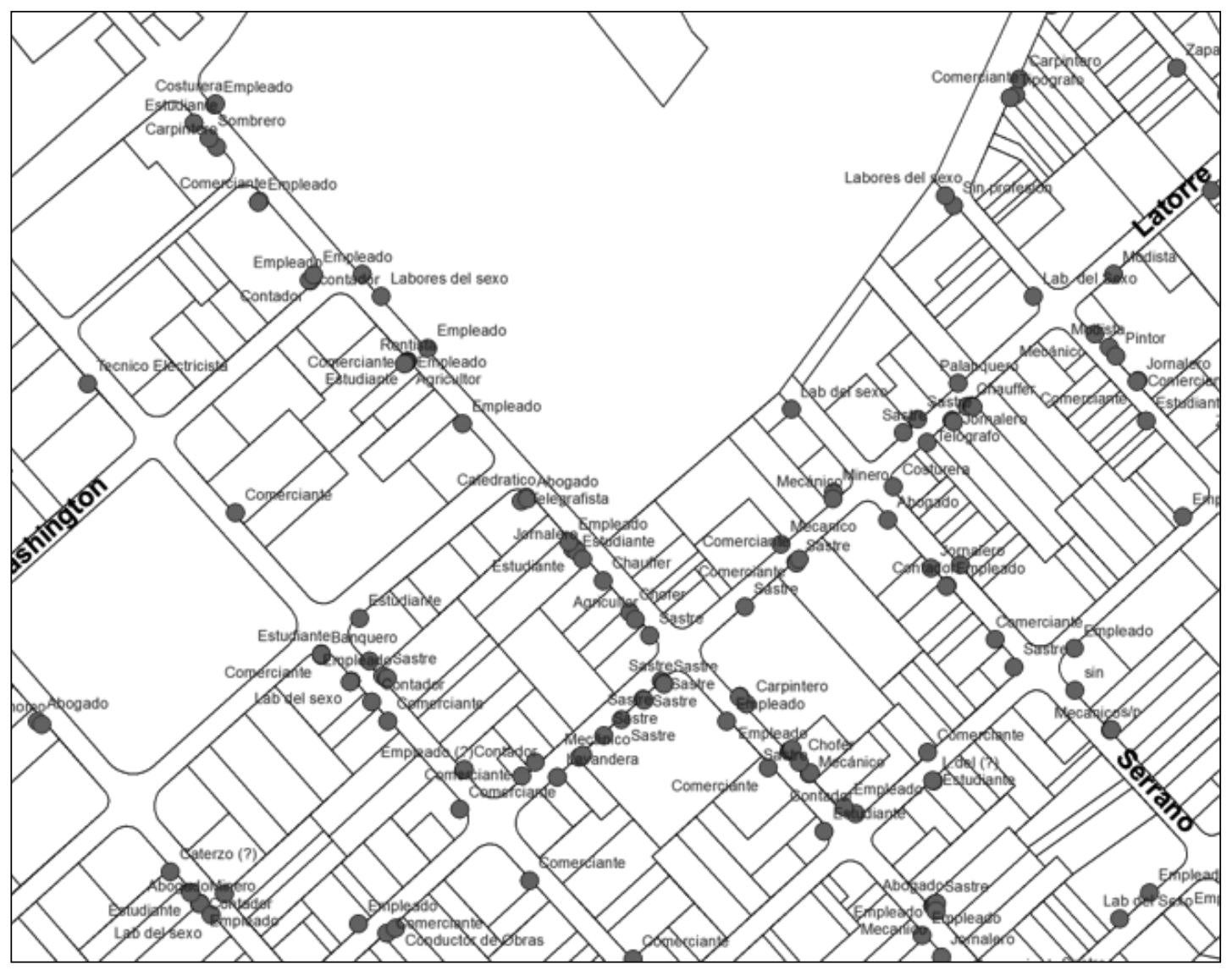

Figura 2 Concentración de bolivianos en el cruce de calles Bolívar y Latorre, con indicación de profesiones. Fuente: Elaboración propia. 
de las capitales. Las fábricas son operaciones ávidas de tierras; en términos generales, si realmente existen en las ciudades, se encuentran en la periferia, donde la tierra es más barata. El taller es la más común de las actividades centralizadas en la ciudad, es a la vez más pequeño y menos mecanizado" (Sennett, 2002, 292).

Si nos detenemos en los sastres, entre los que hay cuatro mujeres, podemos observar otras tendencias, por ejemplo, en su gran mayoría provienen de Cochabamba, que era una ciudad donde destacaba la economía del artesanado, entre ellos estaban las sastrerías. Entre los inmigrantes hay una cantidad de niños y adolescentes, la mayoría son adultos jóvenes hasta los cuarenta años. Un gran número llegó entre las décadas del diez y veinte. Un punto importante que se vuelve a conectar con las redes sociales de los artesanos cochabambinos es el hecho de que 64 de ellos declararon estar relacionados a otros sastres que estaban en la ciudad, o sea, que había una red de sastres que se prolongaba más allá de sus fronteras en torno a núcleos económicos en formación.

Si observamos los siempre admirados sastres bolivianos, 117 en nuestros registros (considerando aquellos que fueron registrados después de 1930, aunque llegaron antes de esa fecha), encontramos una suerte de concentración espacial donde fijaron su residencia en el centro de la ciudad, con algunos núcleos de ciertas calles, y de forma más dispersa en las periferias norte y sur (Tabla 4).

El Álbum de Tarapacá y Antofagasta de 1924, entre los variados comerciantes extranjeros que publicitan, los bolivianos solo difunden sus sastrerías. Son cuatro, la principal de ellas era la Sastrería Inglesa de A. G. Eyzaguirre, fundada en 1911, situada en calle Condell 648, y en cuyo taller trabajaban 10 operarios. También se publicitaba la Sastrería Mérida de Aurelio Mérida, situada en el Portal Harding, en calle Latorre 640, la que se había establecido en 1908 en la ciudad. Acerca de su propietario se anunciaba como un cortador profesional formado en Londres y Nueva York. Su taller empleaba 17 operarios hombres y 7 mujeres, y el sistema de venta estaba basado en un club de ternos de 150 socios que pagaban una cuota semanal, y entre los cuales se sorteaban trajes. Se sumaba la Condal de Víctor Ochoa emplazada en calle Baquedano y establecida en 1910. Ochoa había obtenido su título de cortador en La Paz, empleaba a 3 operarios y utilizaba el servicio de costureras externas, y parte de sus ventas se organizaban en torno a un club de ternos de 50 socios. Por último publicitaba La Porteña de Juan Ricardo Flores en calle Matta 508. Se había establecido en 1914 y estaba orientada a la "juventud elegante". Empleaba a 10 hombres y sorprendentemente a 32 mujeres, tomando en cuenta que las mujeres en los registros de inmigrantes solo 4 declararon ser sastres. Una impresión de las preferencias de localización de los sastres en torno al centro residencial, desde calle San Martín hasta 14 de Febrero, y desde calle Uribe hasta Méndez, se presenta en la Figura 3.

Determinados oficios refirieron a la expansión de la ciudad. Dos costureras, en 1914, fijaron su residencia en calle Saavedra, arteria extrema al sur oriente, mientras un empleado nos indica hacia 1896 que calle Atacama es de las calles más al centrooriente. En 1900 un empleado señala el avance que experimenta la urbe hacia el extremo sur, pues vive en calle Galleguillos Lorca. La calle Huanchaca sirve en 1909 de casa a un empleado en el sector nororiente y un mecánico ese mismo año señala a calle Caracoles como avance hacia el norponiente.

Puede indicarse que fue entre 1906 y 1920 cuando se concentró la presencia de los comerciantes bolivianos en la ciudad. Hubo también una considerable presencia en el centro urbano, como se aprecia en la Figura 4.

Ese segmento fue relevante en la ciudad, pues determinadas casas comerciales y tiendas tienen relaciones mercantiles con homólogos en las ciudades bolivianas (Tabla 5). Manuel Grande Vargas llegó en 1899 desde Oruro, y se instaló como comerciante en calle Adamson (AHE, 55: P. 745). Por la misma época procedente desde La Paz llegó Santiago Estrada L, domiciliándose en calle Maipú 757. Fueron los más antiguos bolivianos en el rubro. En 1900 se establece Nicolás Copa González, nacido en Calama en 1875, casado y se instala en calle San Martín s/n (AHE, 50: P. 13851).

\section{Análisis de los gráficos estadísticos totales de los residentes bolivianos en Antofagasta}

\section{a) Orígenes geográficos y distribución de género de la migración}

Al considerar la información individual contenida en los prontuatrios es posible realizar una caracterización más detallada de la colonia boliviana residente en la ciudad de Antofagasta. En primer 
Tabla 4. El oficio de sastre: procedencia, año de llegada, residencia

\begin{tabular}{|c|c|c|c|c|c|c|c|c|}
\hline Nombre & Ape. Paterno & Ape. Materno & $\begin{array}{c}\text { Año } \\
\text { Filiación }\end{array}$ & $\begin{array}{c}\mathrm{N}^{\circ} \mathrm{de} \\
\text { Prontuario }\end{array}$ & $\begin{array}{c}\text { Año } \\
\text { Nacimiento }\end{array}$ & Provincia & Año Ingreso & Profesión \\
\hline Eleodora & Angulo & Angulo & 1919 & 2152 & 1857 & Cochabamba & 1870 & Sastre \\
\hline Felipe & Rocha & Vargas & 1919 & 420 & 1872 & Cochabamba & 1880 & Sastre \\
\hline Manuel & Castillo & Ayala & 1919 & 1905 & 1888 & Cochabamba & 1885 & Sastre \\
\hline Andres & Hyman & Duarte & 1919 & 7751 & 1872 & Sucre & 1892 & Sastre \\
\hline Eleodoro & Dalenz & Menubia & 1919 & 1102 & 1894 & Cochabamba & 1894 & Sastre \\
\hline Elias & Mariaca & Recabado & 1919 & 1806 & 1884 & SipeSipe & 1898 & Sastre \\
\hline Manuel & Pierola & Camacho & 1919 & 1367 & 1874 & Cochabamba & 1899 & Sastre \\
\hline Primitivo & Sandi & Sanchez & 1919 & 1941 & 1886 & Sucre & 1900 & Sastre \\
\hline Miguel & Valderrama & Gutierrez & 1919 & 2269 & 1900 & Puirata & 1900 & Sastre \\
\hline Jose Toribio & Olachea & Salas & 1919 & 5036 & 1885 & Cochabamba & 1900 & Sastre \\
\hline José & Mérida & Gutierrez & 1919 & 3581 & 1872 & Cochabamba & 1904 & Sastre \\
\hline Aurelio & castillo & Gutierrez & 1919 & 2439 & 1875 & Cochabamba & 1904 & Sastre \\
\hline Jose & Camacho & Rojas & 1919 & 1380 & 1889 & Cochabamba & 1905 & Sastre \\
\hline Prudencio & Mendez & Valdivia & 1919 & 3170 & 1882 & Cochabamba & 1907 & Sastre \\
\hline Mariano & Rojas & Torrico & 1919 & 3492 & 1889 & Cochabamba & 1908 & Sastre \\
\hline Daniel & Guardia & Savedra & 1919 & 2270 & 1896 & Cochabamba & 1908 & Sastre \\
\hline Nestor & Mejias & Claros & 1919 & 4249 & 1890 & Cochabamba & 1910 & Sastre \\
\hline Juan de la Cruz & Contreras & Montain & 1919 & 1477 & 1886 & Cochabamba & 1910 & Sastre \\
\hline Jose & Castro & Sillon & 1919 & 3239 & 1888 & Potosi & 1911 & Sastre \\
\hline Felix & Fernandez & Ponce & 1919 & 3515 & 1879 & Sucre & 1912 & Sastre \\
\hline Aurelio & Ochoa & Perez & 1919 & 5588 & 1897 & Cochabamba & 1916 & Sastre \\
\hline Marcelino & Ledezma & Triviño & 1920 & 9418 & 1869 & Cochabamba & 1890 & Sastre \\
\hline Carmelo & Alvarez & Artiaga & 1920 & 13359 & 1884 & Sucre & 1901 & Sastre \\
\hline Alejandro & Antezana & Rojas & 1920 & 9649 & 1899 & Cochabamba & 1901 & Sastre \\
\hline Juan Ricardo & Flores & Murillo & 1920 & 4531 & 1886 & Sucre & 1904 & Sastre \\
\hline Victor & Ochoa & Perez & 1920 & 9269 & 1888 & Cochabamba & 1905 & Sastre \\
\hline Adolfo & Varela & Gonzalez & 1920 & 8176 & 1893 & Tupiza & 1905 & Sastre \\
\hline Juanito & Hurtado & Cespedes & 1920 & 13236 & 1982 & Cochabamba & 1905 & Sastre \\
\hline José Rosas & Miranda & Céspedes & 1920 & 10417 & 1887 & Cochabamba & 1907 & Sastre \\
\hline Fernando & Claro & Rojas & 1920 & 9929 & 1890 & - & 1909 & Sastre \\
\hline Arturo Guillermo & Eyzaguierre & Eyzaguierre & 1920 & 13472 & 1886 & - & 1910 & Sastre \\
\hline Donato & Rodriguez & Albarta & 1920 & 9661 & 1897 & Cochabamba & 1911 & Sastre \\
\hline Fermin & Rojas & Camacho & 1920 & 9246 & 1883 & Cochabamba & 1915 & Sastre \\
\hline Julio & Cuenca & Cuenca & 1920 & 9065 & 1873 & Potosí & 1916 & Sastre \\
\hline Serafin & Michell & Barriga & 1920 & 9832 & 1889 & Oruro & 1917 & Sastre \\
\hline Casto & Nogales & Villegas & 1920 & 13265 & 1898 & Cochabamba & 1917 & Sastre \\
\hline Jose Hector & Sanjines & Valdes & 1920 & 17305 & 1899 & La Paz & 1920 & Sastre \\
\hline Francisco & Lara & Lara & 1920 & 75837 & 1889 & Cochabamba & 1920 & Sastre \\
\hline Miguel & Plaza & Montero & 1920 & 9892 & 33 años & Cochabamba & - & Sastre \\
\hline Arturo & Vasquez & Montaña & 1921 & 17858 & 1897 & Cochabamba & 1901 & Sastre \\
\hline Samuel & Noeales & Pereira & 1921 & 18894 & 1895 & Cochabamba & 1904 & Sastre \\
\hline Felix & Carvajal & Moscoso & 1921 & 16566 & 1091 & La Paz & 1918 & Sastre \\
\hline Enrique & Rosales & Lloza & 1921 & 15361 & 1898 & $\mathrm{La} \mathrm{Paz}$ & 1919 & Sastre \\
\hline Jose & Flores & Miranda & 1921 & 16098 & 1898 & Potosí & 1919 & Sastre \\
\hline Lorenzo & Escobar & Rojas & 1921 & 18551 & 1885 & $\mathrm{La} \mathrm{Paz}$ & 1919 & Sastre \\
\hline Eleodoro & Zapata & Lopez & 1922 & 29651 & 1895 & Cochabamba & 1910 & Sastre \\
\hline Hilarion & Vareas & Meadez & 1922 & 69388 & 1899 & Quillacollo & 1924 & Sastre \\
\hline Feliciano & Chavez & Rochia & 1923 & 29993 & 1895 & Cochabamba & 1922 & Sastre \\
\hline Fin & Fernandez & Ponce & 1924 & 39798 & 1888 & Sucre & 1904 & Sastre \\
\hline Cristobal & Plaza & Rodríguez & 1924 & 11389 & 1891 & Cochabamba & 1910 & Sastre \\
\hline Caciano & Salvatierra & Otarola & 1924 & 46827 & 28años & Quillacollo & 1920 & Sastre \\
\hline Eulojio & Veliz & Orellana & 1924 & 45783 & 21 años & Quillacollo & 1922 & Sastre \\
\hline Roberto & Silva & Jurado & 1924 & 44776 & 1901 & La Paz & 1924 & Sastre \\
\hline Faustino & Gamboa & Sandoval & 1924 & 109783 & 1905 & Cochabamba & - & Sastre \\
\hline Nicolas & Vargas & Lumel & 1924 & 420630 & 27 años & Potosí & - & Sastre \\
\hline
\end{tabular}




\begin{tabular}{|c|c|c|c|c|c|c|c|c|}
\hline Nombre & Ape. Paterno & Ape. Materno & $\begin{array}{c}\text { Año } \\
\text { Filiación }\end{array}$ & $\begin{array}{c}\mathrm{N}^{\circ} \mathrm{de} \\
\text { Prontuario }\end{array}$ & $\begin{array}{c}\text { Año } \\
\text { Nacimiento }\end{array}$ & Provincia & Año Ingreso & Profesión \\
\hline Fortunado & Corrales & Zurita & 1925 & 59589 & 1850 & Cochabamba & 1879 & Sastre \\
\hline Nicolas & Mendez & Moreira & 1925 & 59917 & 1878 & Cochabamba & 1908 & Sastre \\
\hline Jose & Gutierres & Ponce & 1925 & 50290 & 1901 & La Paz & 1920 & Sastre \\
\hline Jose Manuel & Montaño & Orellana & 1925 & 48880 & 1888 & Cochabamba & 1920 & Sastre \\
\hline Gregario & Delgado & Fomel & 1925 & 64979 & 1898 & La Paz & 1925 & Sastre \\
\hline Agápitoluis & Pereira & Arévalo & 1925 & 57971 & 1897 & Cochabamba & Sastre & Sastre \\
\hline Manuela & Escobar & Miranda & 1926 & 45871 & 1899 & La Paz & 1888 & Sastre \\
\hline Miguel & Ruiz & Estrada & 1926 & 63684 & 1896 & Potosí & 1896 & Sastre \\
\hline Jose Gabriel & Piroz & Estrada & 1926 & 66644 & 1890 & Potosí & 1903 & Sastre \\
\hline Néstor & Maceda & Cáceres & 1926 & 71914 & 1892 & La Paz & 1908 & Sastre \\
\hline Julio & Mérida & Perez & 1926 & 70359 & 1901 & Cochabamba & 1913 & Sastre \\
\hline Roberto & Vargas & Guzman & 1926 & 69453 & 1903 & Sucre & 1913 & Sastre \\
\hline Celestina & Merida & Perez & 1926 & 64144 & 1900 & Cochabamba & 1914 & Sastre \\
\hline Luis & Montecino & Ames & 1926 & 25219 & 1906 & Cochabamba & 1917 & Sastre \\
\hline René & Sanjines & Tejada & 1926 & 76599 & 1896 & La Paz & 1919 & Sastre \\
\hline Carlos & Gaudi & Lacerna & 1926 & 71913 & 1902 & Tupiza & 1919 & Sastre \\
\hline Daniel & Allendes & Guzman & 1926 & 64217 & 1904 & Cochabamba & 1923 & Sastre \\
\hline Erasmo & Vareas & Rodriguez & 1926 & 64648 & 1897 & Cochabamba & 1923 & Sastre \\
\hline Dionicio & Parrilla & García & 1926 & 62288 & 1883 & La Paz & 1923 & Sastre \\
\hline Pablo & Espinoza & Cauchan & 1926 & 67656 & 1906 & $\mathrm{La} \mathrm{Paz}$ & 1923 & Sastre \\
\hline Tomas & Reina & Ramírez & 1926 & 68175 & 1889 & $\mathrm{La} \mathrm{Paz}$ & 1923 & Sastre \\
\hline Jose & Arce & Pantoja & 1926 & 65459 & 1888 & Cochabamba & 1924 & Sastre \\
\hline Antonio & Martinez & Adones & 1926 & 68476 & 1888 & Potosí & 1924 & Sastre \\
\hline Ricardo & Camacho & Rojas & 1926 & 65297 & 1901 & Cochabamba & 1926 & Sastre \\
\hline Simon & Crespo & Rojas & 1926 & 65353 & 1902 & Potosí & 1926 & Sastre \\
\hline Demetrio & Quiroga & Llanos & 1926 & 108921 & 1916 & Quillacolla & - & Sastre \\
\hline Jeraldo & Saavedra & Duran & 1927 & 79914 & 1878 & Cochabamba & 1894 & Sastre \\
\hline Sebastian & Cejas & Romero & 1927 & 79290 & 1886 & Cochabamba & 1912 & Sastre \\
\hline Juan & Ferrer & Aguilar & 1927 & 77068 & 1892 & Potosí & 1912 & Sastre \\
\hline Florencio & Nogales & Pereira & 1928 & 82159 & 1895 & Cochabamba & 1906 & Sastre \\
\hline Benancio & Mercado & Gongora & 1928 & 29642 & 1907 & Cochabamba & 1907 & Sastre \\
\hline Humberto & Quiroga & Gutierrez & 1928 & 57025 & 1896 & Charcas & 1921 & Sastre \\
\hline Miguel & Ortiz & Kolca & 1928 & 82169 & 1902 & Punata & 1926 & Sastre \\
\hline Agustin & Vera & Cutipa & 1929 & 3660 & 1897 & $\mathrm{La} \mathrm{Paz}$ & 1914 & Sastre \\
\hline Daniel & Valderrama & Gutierrez & 1929 & 990 & 1891 & Cochabamba & 1919 & Sastre \\
\hline Benigno & Vargas & Montaña & 1929 & 87161 & 1881 & Cochabamba & 1921 & Sastre \\
\hline Trifon & Viltarroel & Figueroa & 1929 & 89995 & 1907 & Cochabamba & 1928 & Sastre \\
\hline Teófilo & Peredo & Aguilar & 1929 & 89873 & 1903 & Cochabamba & 1929 & Sastre \\
\hline Sebastian & Ledesma & Carmena & 1930 & 141197 & 1896 & Cochabamba & 1904 & Sastre \\
\hline Casiano & Rios & Fernandez & 1930 & 102181 & 1905 & Sucre & 1929 & Sastre \\
\hline Gregario & Patiño & Zambrano & 1931 & 103204 & 1862 & Cochabamba & 1899 & Sastre \\
\hline Daniel & Veliz & Montaño & 1931 & 103558 & 1886 & Cochabamba & 1905 & Sastre \\
\hline Timoteo & Cejas & Salvatierra & 1931 & 104090 & 1876 & Antofagasta & 1910 & Sastre \\
\hline Zeinon & Espinoza & Rodríguez & 1931 & 104871 & 1905 & Cochabamba & 1928 & Sastre \\
\hline Santiago & Ocampo & Vasquez & 1933 & 49144 & 1880 & La Paz & 1912 & Sastre \\
\hline Alberto & Rodriguez & Rios & 1933 & 107337 & 1913 & Oruro & - & Sastre \\
\hline Justino & Gamboa & Sandoval & 1934 & 109783 & 1905 & Cochabamba & - & Sastre \\
\hline Justiniano & Mejias & Solis & 1935 & 114835 & 1887 & Cochabamba & 1910 & Sastre \\
\hline Pablo & Mercado & Verántequi & 1937 & 119488 & 1913 & La Paz & 1927 & Sastre \\
\hline Alberto & Torres & Eyzaguirre & 1938 & 120609 & 1914 & $\mathrm{LaPaz}$ & 1925 & Sastre \\
\hline Raul & Zambrano & lriarte & 1941 & 51228 & 1906 & Tarata & 1911 & Sastre \\
\hline Juan & Olmos & Rivera & 1942 & 132746 & 1920 & Cochabamba & Sastre & \\
\hline Abdon & Ledesma & Rocha & 1895 & - & - & Cochabamba & 1920 & Sastre \\
\hline Rajoel & Zerraz & Cespedes & 1893 & - & - & Cochabamba & 1920 & Sastre \\
\hline OscarFranci & Roías & Ca macho & - & 83736 & 1901 & Puna ta & 1922 & Sastre \\
\hline Agustín & Ríos & Siles & - & 101400 & 1888 & Quillacolla & 1929 & Sastre \\
\hline
\end{tabular}

Fuente: Elaboración propia. 


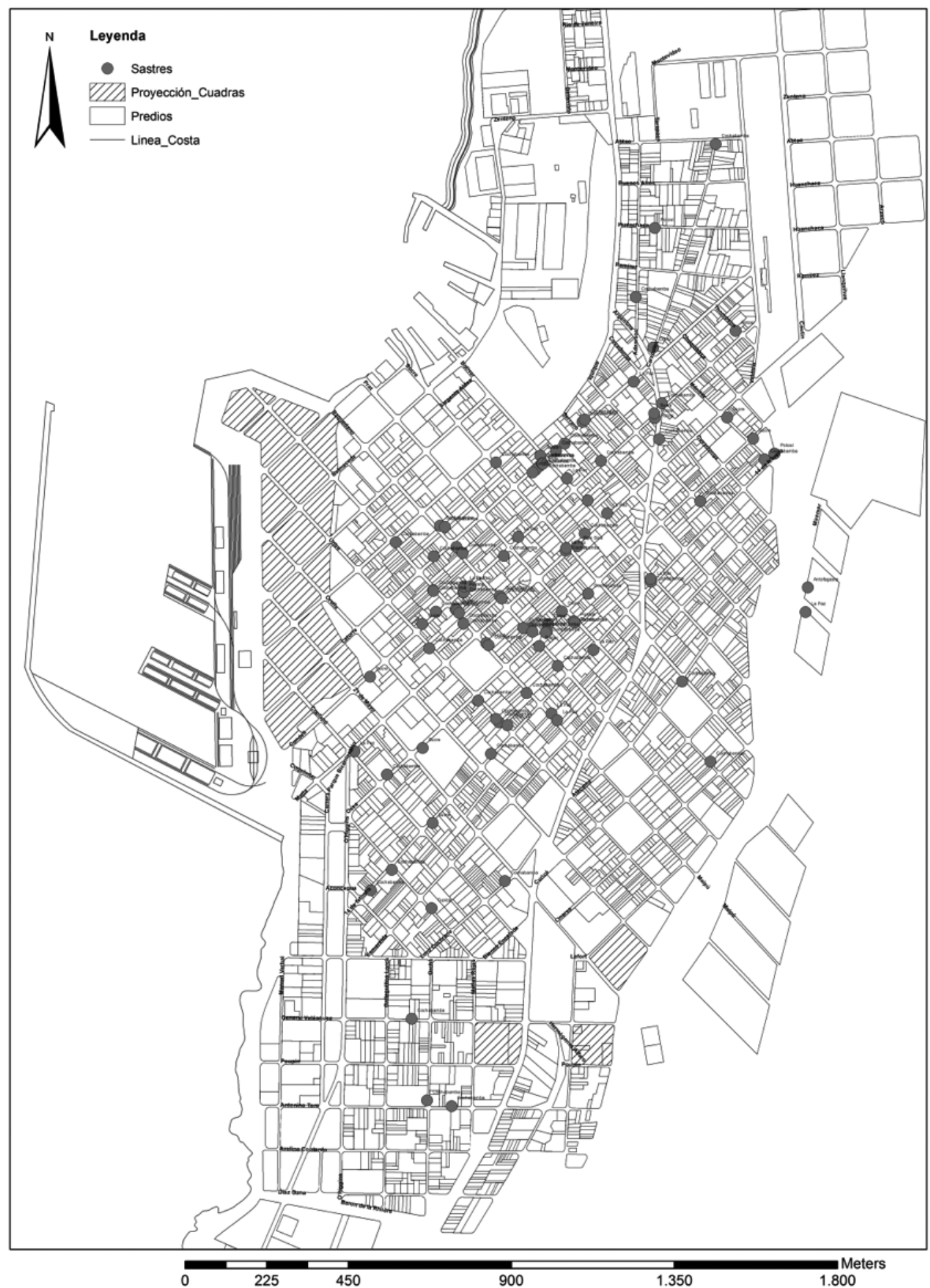

Figura 3 Sastres bolivianos en Antofagasta, con lugar de origen. Fuente: Elaboración propia. 


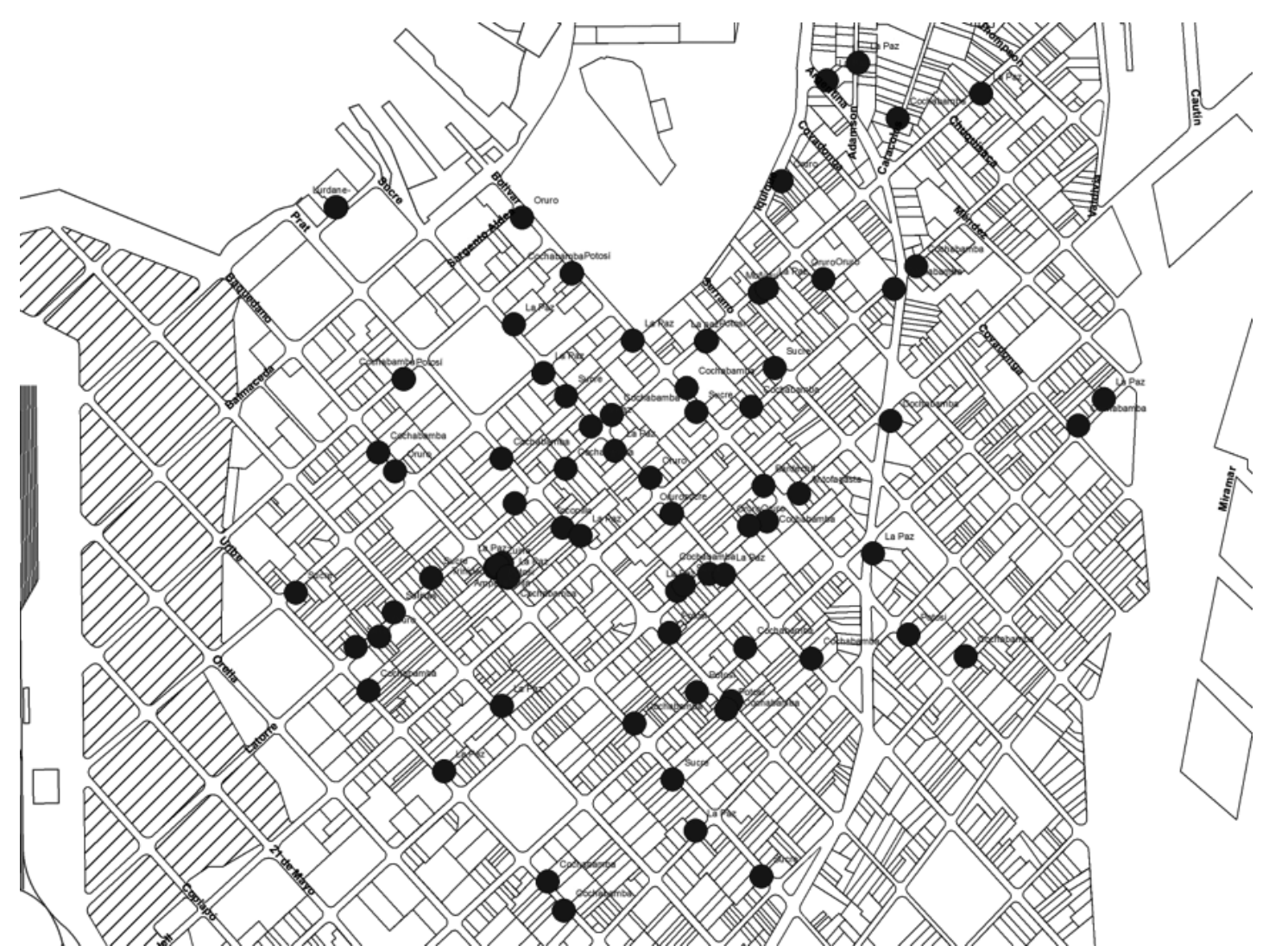

Figura 4 Comerciantes bolivianos en Antofagasta, con indicación de lugar de origen.

Fuente: Elaboración propia.

Tabla 5. Comerciantes bolivianos radicados en Antofagasta durante el ciclo salitrero (Selección)

\begin{tabular}{|c|c|c|c|c|c|}
\hline Nombre & Procedencia & Año de llegada & Estado civil & Domicilio & Prontuario \\
\hline Antonio Mendizábal Benavente & $\mathrm{LaPaz}$ & 1931 & Casado & Hotel Plaza & $\mathrm{N}^{\mathrm{o}} 105375$ \\
\hline Víctor Castañón Melcar & Chuquisaca & 1930 & Soltero & Sucre 522 & $\mathrm{~N}^{\circ} 102296$ \\
\hline Jorge Ledezma Sáinz & $\mathrm{LaPaz}$ & 1929 & Casado & Hotel Plaza & $\mathrm{N}^{\mathrm{o}} 102864$ \\
\hline Ester Bustillo Jáuregui & $\mathrm{LaPaz}$ & 1927 & Casada & Latorre 922 & $\mathrm{~N}^{\circ} 90029$ \\
\hline Arturo Estrada Lorna & $\mathrm{LaPaz}$ & 1926 & Soltero & Bolívar 429 & $N^{o} 76856$ \\
\hline José Rada Reina & $\mathrm{LaPaz}$ & 1926 & Soltero & Pensión Flor del Norte & $\mathrm{N}^{\mathrm{o}} 73920$ \\
\hline Eladio Mendoza Benavente & Sucre & 1925 & Casado & Prat esq. Matta & $\mathrm{N}^{\mathrm{o}} 57921$ \\
\hline Luis Maidana Suárez & $\mathrm{LaPaz}$ & 1925 & Casado & Sin dirección & $\mathrm{N}^{\circ} 42661$ \\
\hline Antonio García Fernández & Oruro & 1924 & Casado & 14 de Febrero 1211 & $\mathrm{~N}^{\circ} 64728$ \\
\hline Carlos Echava Sánchez & Cochabamba & 1920 & Casado & Matta s/n & $\mathrm{N}^{\circ} 15138$ \\
\hline Florencio Delgado Cossio & La Paz & 1920 & Casado & Hotel Español & $\mathrm{N}^{\circ} 12907$ \\
\hline Max Gastelú Larrañaga & Oruro & 1920 & Casado & Hotel Líbano & $N^{\circ} 41318$ \\
\hline Ernesto Jordán Cortés & $\mathrm{La} \mathrm{Paz}$ & 1920 & Casado & Sucre 220 & $\mathrm{~N}^{\circ} 14924$ \\
\hline Pascual Muñoz Vargas & Oruro & 1920 & Soltero & Latorre $s / \mathrm{n}$ & $\mathrm{N}^{\mathrm{o}} 15051$ \\
\hline Isaac Pizarro Velasco & Sucre & 1920 & Soltero & San Martín 118 & $\mathrm{~N}^{\mathrm{o}} 15989$ \\
\hline Félix González Balarza & Sucre & 1919 & Soltero & Riquelme 143 & $\mathrm{~N}^{\circ} 40824$ \\
\hline Jerónimo Matulic Gosponestic & Oruro & 1918 & Casado & Residencial O'Higgins & $\mathrm{N}^{\circ} 9898$ \\
\hline José Medina Román & Sucre & 1917 & Soltero & Bolívar 460 & $\mathrm{~N}^{\circ} 879$ \\
\hline Víctor de la Peña Ballivián & $\mathrm{LaPaz}$ & 1917 & Soltero & Hotel Buenos Aires & $\mathrm{N}^{\circ} 12907$ \\
\hline Ricardo Hernández Pereira & Cochabamba & 1916 & Soltero & Pensión Progreso & $\mathrm{N}^{\circ} 1521$ \\
\hline Francisco Huerta Flores & Potosí & 1911 & Casado & Plaza Hotel & $\mathrm{N}^{\circ} 18854$ \\
\hline Agustín Huara Mamani & $\mathrm{LaPaz}$ & 1910 & Casado & Latorre s/n & $\mathrm{N}^{\circ} 9515$ \\
\hline
\end{tabular}

Fuente: Elaboración propia. 
lugar se considera el lugar de origen en Boliva, información que ha sido agregada a nivel de la división política administrativa departamental para efectos de lograr una mayor comparabilidad. En la Tabla 6 se presenta la distribución relativa según el departamento de origen y según sexo.

En términos de flujos totales, los departamentos de Cochabamba y La Paz explican el 57\% de los flujos, mientras que los departamentos de Potosí, Chuquisaca y Oruro aportan el 34\% adicional, estando el origen del resto de la inmigración fragmentada en su origen en el resto de los departamentos, en el extranjero o poco claro. En términos de composición se trata de una inmigración dominantemente masculina (83\%) con seguridad asociada a búsqueda de nuevos horizontes laborales y motivada por mejores condiciones económicas. Las mujeres también provienen de Cochabamba y La Paz (61\%) y en menor medida de Potosí, Chuquisaca y Oruro (29\%).

\section{b) Capital social del migrante y etapas temporales de la inmigración}

Con relación a las ocupaciones desarrolladas por los inmigrantes, 15 tipos de trabajo concentran la mayor parte de los empleos ( $81 \%$ de los casos). En la Tabla 7 se muestra esta información. En él se destaca que las categorías asociadas a calificaciones técnicas son numerosas e importantes (por ejemplo: sastres, contadores, comerciantes, empleados y mecánicos), lo que configura a este grupo migratorio en una inserción social particular como miembros de una clase de pequeños propietarios, comerciantes o empleados, lo que devendría en la clase media chilena en las décadas siguientes

\section{Cuando se controla la información por} periodo de entrada a Chile, se revela que la migración ocurrió en términos generales durante comienzos del siglo XX, particularmente concentrada en lo subperiodos del 1900-1917 (31\%) y el 1918-1930 (43\%). La migración temprana (siglo XIX) es mucho menor $(8 \%)$.

El origen de esta migración por periodo también pone de manifiesto que las migraciones de Cochabamba y La Paz no solo son mayores en flujos sino que tienen más historia, ellas concentran el $61 \%$ de los migrantes anteriores al 1900.

Tabla 6. Participación \% en total migración de Antofagasta según origen en Bolivia: Prontuarios periodo 1901-1930.

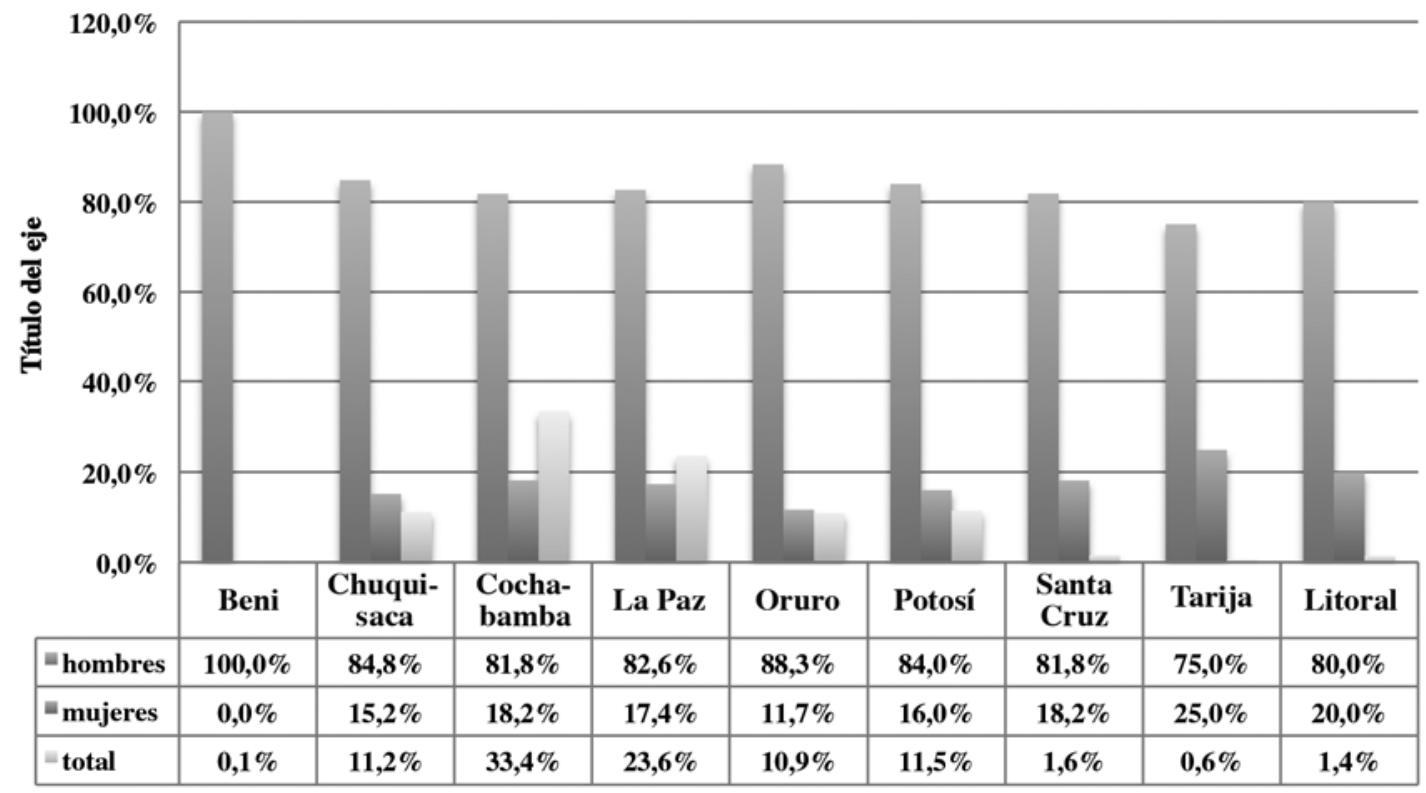

Fuente: elaboración propia basado en el Archivo Histórico de Extranjería del Servicio de Registro Civil e Identificación: Bolivia. Notas: Las filas 1 y 2 representan la composición relativa por sexo de la población migrante según su departamento de origen en Bolivia. La fila 3 representa la participación de cada departamento en el total de migrantes desde ese país hacia Chile 
Tabla 7. Ocupaciones principales migrantes bolivianos en Antofagasta: 1901-1930.

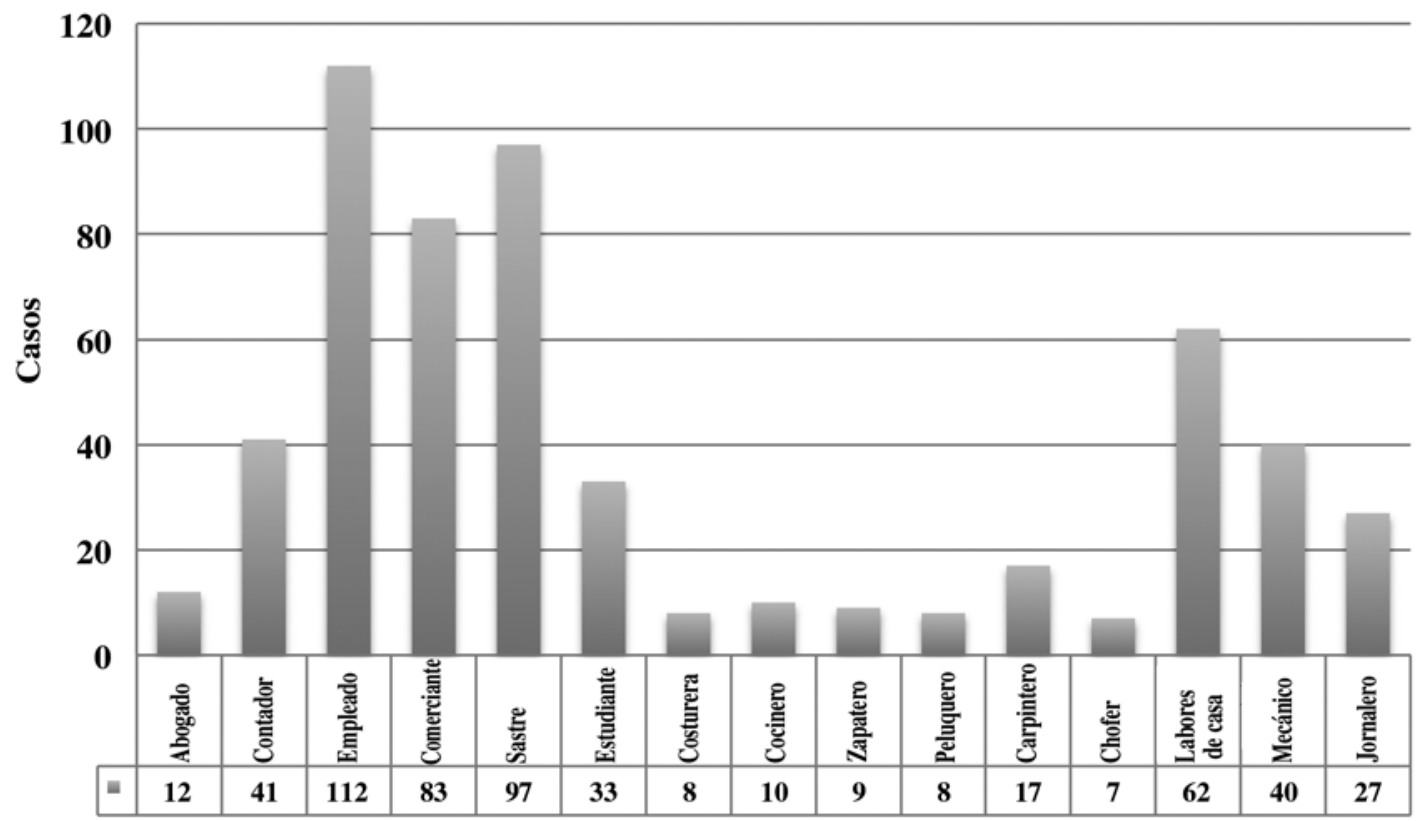

Fuente: elaboración propia basado en el Archivo Histórico de Extranjería del Servicio de Registro Civil e Identificaciones: Bolivia

El periodo siguiente de 1900 a 1917 presenta una mayor diversificación de orígenes, con apariciones de lugares de procedencia más exóticos, incluso de ciudadanos bolivianos residentes fuera de Bolivia. Finalmente el último periodo, 1918-1930, aporta un mayor volumen de casos, muy concentrados en Cochabamba y La Paz (44\%) y con una participación menor pero muy similar de Chuquisaca, Oruro y Potosí (en torno al $12 \%$ cada departamento).

\section{c) Grupos etarios del migrante}

En la Tabla 8 se presenta la distribución de edad de la población inmigrante. Esta información es relevante para caracterizar las potencialidades del flujo migratorio en cuanto fuerza de trabajo para la comunidad receptora. Ya se han destacado las condiciones económicas que dominaban el proceso de fundación y consolidación de la ciudad y la preeminencia de la industria salitrara que generaba una constante demanda de nuevos trabajadores, de diversas calificaciones y con condiciones físicas que permitieran adaptarse exitosamente a las cualidades ambientales del desierto y a los rigores de la industria misma.
La información indica una alta concentración en grupos jóvenes (64\% de los casos), hasta 30 años, lo que indica que se trata de migrantes orientados a desarrollar un proyecto de vida en la comunidad de recepción y de alta empleabilidad en el mercado laboral local. Debe notarse también que la presencia de adultos mayores a 50 años es prácticamente inexistente (solo el 2\%), lo que refuerza la idea de que se trata de una inmigración con una considerable asociación a la inclusión a la vida económica, como trabajadores activos en la comunidad.

\section{d) Composición étnica}

Un aspecto del que no se ha reparado lo suficiente, cuando el componente demográfico migrante está compuesto de poblaciones criollas e indígenas, es plantearse cuál y cómo estos segmentos se ha integrado en las ciudades principales, en este caso en Antofagasta.

Los datos que nos refiere el fondo documental que empleamos señalan que la población boliviana asentada en Antofagasta mayoritariamente, casi en su totalidad, fue de ascendencia hispana, no faltando patronímicos europeos no latinos. Los pocos 
Tabla 8. Distribución de edad de inmigrantes bolivianos a Antofagasta.

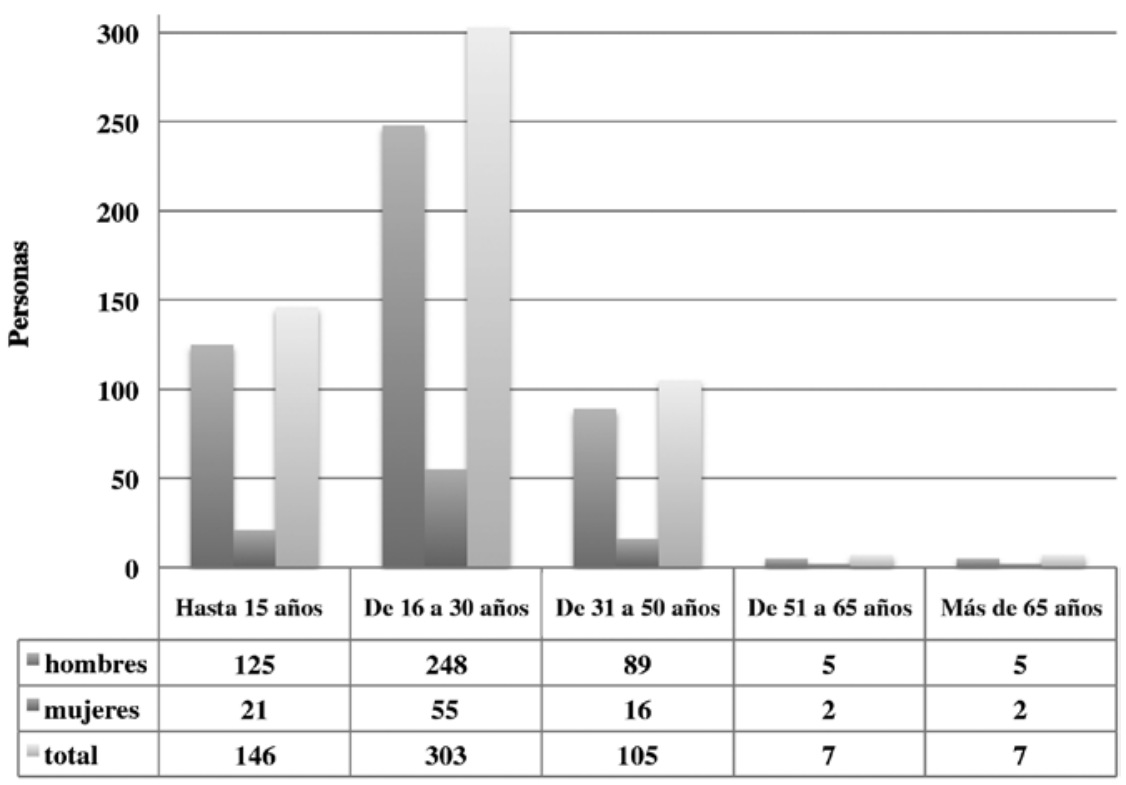

Fuente: elaboración propia basado en el Archivo Histórico de Extranjería del Servicio de Registro Civil e Identificaciones: Bolivia

apellidos de procedencia aymara, no faltando un par de quechua, nos plantean que su condición de capital social era cualificada, esto pudo haber influido en la decisión de establecerse en Antofagasta.

Carmen Catacora (Qatacura) Vargas (Prontuario 9547), nacida en 1902 en La Paz, llegó a principios de la década de 1930, sabiendo leer y escribir. Casada con Víctor Blanco Mercado, se desenvolvió como dueña de casa (labores del sexo, se clasificaba en la época), señalando dos relaciones sociales en la urbe, a nivel de empleados.

Marcelo Colque (Qullqui) Choque (P. 59637) arribó desde Uyuni. Alfabetizado, aprendió el oficio cualificado de mecánico y fijó su domicilio en Avenida Argentina 575. Se relacionó con Teodoro Ramos Latorre, contratista, y Miguel Allende, empleado.

Arturo Condore (Kunturi) Condore (P. 7247), partió desde La Paz hacia Antofagasta en 1912, con la experiencia de ser chofer, situación que le permitió su condición de alfabetizado. En la ciudad vivió en varias partes, en Adamson 390, Ossa 1159 y Maipú 150.

Nicolás Copa (Kupa) Verzulez (P. 13851) llegó en 1900 desde un poblado denominado Nolipio (sic), con instrucción primaria, casado con Andrea Ballestero, se dedicó al comercio, instalándose en calle San Martín.
Alberto Cusicanqui (Kusikanki) Martínez (P. 1527) viajó desde La Paz en 1905 a la edad de diez años. Estudió en Antofagasta y se tituló de contador, posiblemente en el Instituto Comercial. Soltero. Sus relaciones lo vincularon con el Servicio del Registro Civil e Identificaciones, con un empleado y el jefe de identificaciones.

María Cusicanqui Soto (P. 1200056), nacida en 1898, debió haber ingresado a fines de la década de 1920. Instruida en lo básico, se casó con Víctor Clippe Meleros, de quien enviudó. Fue dueña de casa, en su hogar de calle Sucre 320.

Antonio Guamán (Guamán) Salinas (P. 117997) llegó desde Cochabamba a principios de 1930, como estudiante, instalándose en calle Bolívar 240.

Francisco Guchalla (Wachalla) Guanchilla (P. 154412) provenía desde La Paz, llegando a Antofagasta en 1922 como contador, casado con Rosa Elorrienda, y se estableció en calle Washington.

Agustín Huaca (Waka) Mamani (Mamani), nacido en 1868, se había establecido en Santiago de Chile, desde donde se trasladó a Antofagasta en 1910. Si bien era analfabeto, pudo desenvolverse como comerciante, con el apoyo de su mujer Manuela Peralta, en calle Latorre. 
El patronímico Mamani (Mamani) fue el más representativo de la etnia aymara en Antofagasta.

Telésforo Mamani Rodríguez (P. 62999) llegó a la ciudad en 1913, soltero y el oficio que declaró fue ser "chanflero".

El contingente principal de la familia Mamani, el grupo más representativo de la etnia aymara en Antofagasta, se localizó en la precordillera, desenvolviéndose en la estación ferroviaria de Cebollar, y en las minas de Collahuasi y de Chuquicamata.

\section{e) Patrones de nupcialidad}

Es importante señalar dos observaciones respecto del concepto de nupcialidad: una, que apunta a un rasgo del grado o un indicador de la inserción de la comunidad inmigrante en el seno de la sociedad regional, a base de las nociones de exogamia, endogamia o endogamia encubierta; dos, que en los sectores populares de la inmigración de raíz latinoamericana es posible que las relaciones de uniones consensuadas, no legales ni sacramentales, haya sido en un porcentaje mayor de lo que se pueda inferir en el cotejo entre la cantidad de solteros (as) y los efectivamente que se acogieron a la institución matrimonial (Salazar y Tisnes 2013). En tal sentido, es factible considerar si en los segmentos inmigratorios se dio el denominado "modelo tradicional de matrimonio", es decir, las edades tardías en las primeras nupcias y una alta proporción de soltería definitiva, que prevaleció en Europa hasta las primeras décadas y que se extendió en España hasta mediados del siglo XX (Hajnal 1965; Castro 1999). Hubo una covarianza entre la soltería definitiva y el retraso del matrimonio y viceversa, ha puntualizado Rowland (1988).

Importa también puntualizar que en el caso de países latinoamericanos con elevados porcentajes de extranjeros, se verificó, como en el caso argentino, que la nupcialidad fue más marcada entre los inmigrantes que en los miembros de la población nativa (Celton, 2008). Y a esto se agregó otra variable: que el traslado del matrimonio desde la esfera eclesial hacia el ámbito civil incidió en el descenso de la nupcialidad, tanto en áreas de bajo nivel de urbanización o bien no fue registrado en la Oficina del Registro Civil, en ciudades intermedias, cuando gravitó con fuerza su adscripción religiosa católica (Valdés 2007; Estrada 2012).

En el proceso de integración en la sociedad receptora, la nupcialidad jugó un papel importante en la fisonomía de la estructura social de esta y, en tal lineamiento, el matrimonio mixto coadyuvó a dicho proceso (Coleman 1993, citado por Sanjurjo 2005).

Sin embargo, como ha reparado Estrada (2012), habrá que tener presente el índice de masculinidad para saber si el matrimonio mixto se llevó a cabo por el varón o la mujer, pues como acota Baldomero Estrada:

\begin{abstract}
El comportamiento matrimonial de las colectividades se conoce por el comportamiento femenino... agreguemos que era común que se manifestaran comportamientos de endogamia encubierta y es el caso en que los extranjeros aparecen contrayendo matrimonio con un o una chilena, cuando en realidad se trata de una descendiente de la nacionalidad a la cual pertenecen pero por haber nacido en Chile se le identifica como nativa (Estrada 2012: 75). Y esto era válido para las colonias europeas.
\end{abstract}

Sin embargo, en las colonias latinoamericanas (hemos cotejado los prontuarios de peruanos, argentinos, colombianos, ecuatorianos, etc.), a diferencia de las europeas (se ha compulsado los prontuarios de británicos, alemanes, franceses, españoles, etc.), se aprecia una inclinación por el matrimonio mixto, posiblemente debido al alto índice de masculinidad y la necesidad de insertarse en la sociedad regional de modo más pleno, no solo en el mercado laboral sino una integración espacial en la urbe que se ve complementada con la nupcialidad con una persona nativa.

A estas características no escapó el contingente boliviano con residencia en Antofagasta.

En el análisis acerca de los patrones de nupcialidad observados en el contingente inmigratorio boliviano, obtenemos los siguientes datos:

1. La información proviene de los libros de matrimonios anuales del Servicio del Registro Civil y de Identificación de Antofagasta (distinto de los prontuarios del Archivo Histórico de Extranjería del Servicio del Registro Civil y de Identificación de Antofagasta, que hemos utilizado en páginas superiores). Para el periodo en análisis solo el libro correspondiente a 1899 se encuentra extraviado, por lo que no hay información para dicho año.

2. Se ha tomado cuenta del número de personas de nacionalidad boliviana que ha contraído matrimonio civil con un(a) contrayente de nacionalidad 
boliviana, caso calificado de matrimonio endogámico, o con un contrayente de nacionalidad diferente, sea chileno(a) o extranjero, caso calificado de matrimonio exogámico.

3. La información ha sido recogida en la Tabla 9, que representa el número de personas involucradas en ambos tipos de matrimonios como $\%$ del total de matrimonios de grupo de estudio ocurridos en casa año, así se percibe con claridad la intensidad relativa de cada tipo de matrimonio endogámico vs. exogámico.

4. Durante el periodo total en análisis, desde 1885

a 1930, 595 ciudadanos(as) bolivianos(as) contraen matrimonio, de ellos 250 lo hacen en modalidad endogámica (42\%) y el resto, 345 , lo hace en forma exogámica (58\%). Lo que define la tendencia global de la conducta del grupo.

Esto se traduce en los resultados estadísticos pormenorizados anualmente:

\section{Conclusiones}

Los flujos migratorios de la población boliviana hacia la ciudad de Antofagasta, en particular, reflejaron, por un lado, que estos se acrecentaron después de 1904, de modo notable, habiendo recibido un impulso con el establecimiento del ferrocarril entre Antofagasta y Oruro y, por otro, constituyeron una demografía que rompió lo fáctico y lo perceptivo respecto del grado de alfabetización que poseía la nación de Bolivia en aquellos años: fue una población inmigrante notoriamente alfabetizada, compuesta en su mayoría por personas criollas y en una ínfima porción por ascendientes indígenas, que poseía un grado de capacitación especializada en sus oficios, por ejemplo de sastre o mecánico, o cierta profesionalización como fueron los abogados, contadores. Constituyó un segmento que supo aprovechar las bondades de una ciudad cosmopolita y de una sociedad progresista, abierta a distintas clases de inmigración que hacia 1907 llegó a contabilizar el $20 \%$ de la población. Los estrechos lazos mercantiles entre casas comerciales de Antofagasta y en Bolivia pudieron ser utilizados por el segmento importante de los comerciantes y por cierto de los empleados.

Los factores de constituir Chile un país orientado por políticas liberales, principalmente en la amplia libertad de tránsito transfronterizo, de fomentar emprendimientos privados comerciales, ofertas de empleo en un mercado laboral dinámico por el empuje salitrero, se unieron a las externalidades positivas de encontrar el boliviano maneras de vida cotidiana próxima a las ciudades mayores de Bolivia, como eran La Paz y Cochabamba, desde donde provino más del $60 \%$ de sus migrantes, ello abrió las posibilidades de comprender las pautas socioculturales o los habitus bourdieanos de los sectores mesocráticos, como los populares, de la sociedad regional y sopesar

Tabla 9. Patrones de nupcialidad de los bolivianos: porcentajes 1885-1930

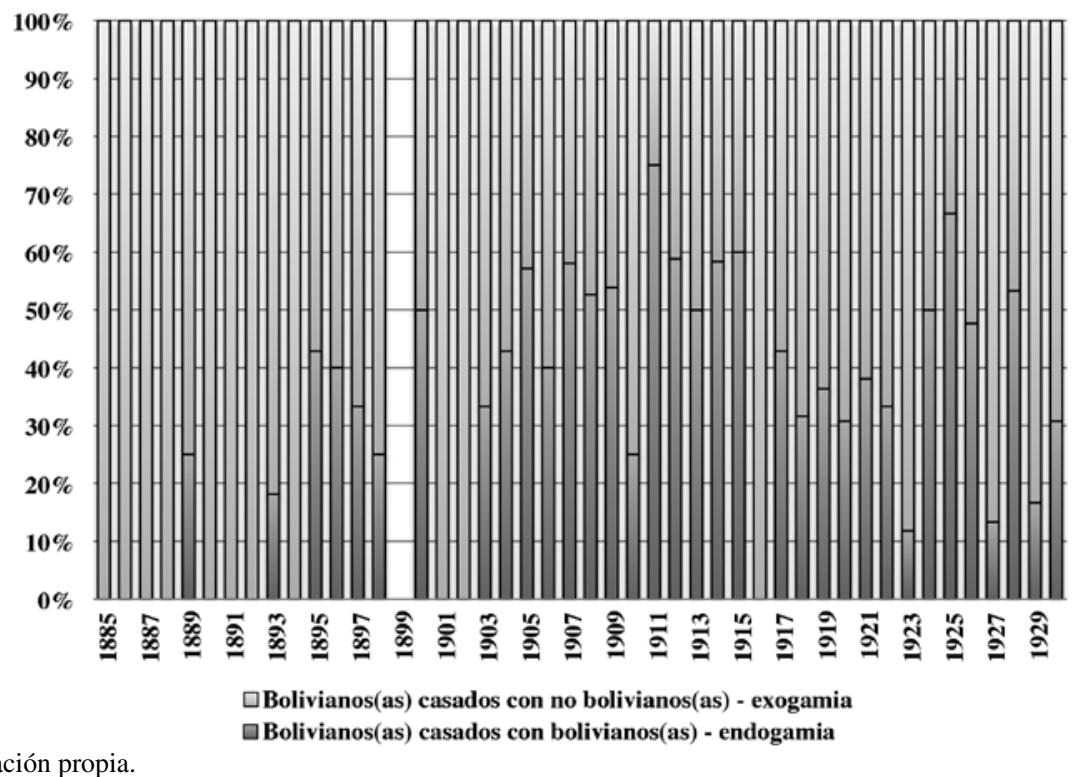

Fuente: Elaboración propia. 
los costos/beneficios de sus proyectos personales y familiares lejos de su país natal.

La migración boliviana, para el caso de Antofagasta, fue mayoritariamente masculina y joven, de ascendencia criolla, y de regiones alejadas de las aledañas a la frontera chilena, y su inserción en la sociedad regional se realizó tanto por medio de su incorporación al mercado laboral como, en cierta forma, mediante sus patrones de nupcialidad donde la exogamia fue mayor que la conducta endogámica mostrada.

\section{Referencias Citadas}

\section{Bibliografía}

Ahumada, María Teresa 1985. Huanchaca, el establecimiento industrial de Playa Blanca en Antofagasta. Ediciones Universidad José Santos Ossa. Antofagasta.

Alarcón, J. Ricardo 1925 Bolivia en el primer centenario de su independencia. Homenaje a Bolivia en el primer centenario de su independencia, Londres.

Bermúdez, Oscar 1963 Historia del salitre desde sus orígenes hasta la Guerra del Pacífico. Santiago de Chile, Ediciones de la Universidad de Chile.

Blakemore, Harold

1996 Historia del Ferrocarril de Antofagasta a Bolivia. 1888-1988. Santiago de Chile, Impresos Universitarios. Original inglés 1990.

Carvalho, Ruber

2010 Manual de Historia de Bolivia. Una visión desde la llanura. Santa Cruz de la Sierra, Imp. Landívar S. R. L.

Castro M. Teresa

1999 Pautas recientes en la formación de pareja. Revista Internacional de Sociología, RIS. Instituto de Estudios Sociales Avanzados, CSIC. $3^{\circ}$ Época, № 23 , mayo-agosto 1999, pp. 61-94.

Celton, Dora

2008 Formación de la familia argentina. Cambios y continuidades. El caso de Córdoba. Temas Americanistas, $\mathrm{N}^{\circ} 21$, julio-diciembre, pp. 16-33.

Couyoumdjian, Juan Ricardo

1986. Chile y Gran Bretaña durante la primera guerra mundial y la postguerra, 1914-1921. Santiago de Chile, Editorial Andrés Bello- Ediciones Universidad Católica de Chile.

Dirección General de Estadística

1931 Resultados del X Censo de la Población efectuado el 27 de noviembre de 1930 y estadísticas comparativas con censos anteriores, Santiago, Imprenta Universo. 3 vols.

Estrada T. Baldomero

2012 Desarrollo empresarial urbano e inmigración europea: españoles en Valparaíso, 1880-1940. Universidad Complutense de Madrid. Memoria para optar al Grado de Doctor. Madrid.

Gajardo, Enrique y Rodríguez Rojas, E. (Editores) 1924 Álbum de Tarapacá y Antofagasta. Antofagasta.

González Miranda, Sergio

2011 Las históricas relaciones entre Tarapacá y Oruro: la frustrada tentativa de integración transfronteriza durante el ciclo de expansión del salitre (1864-1928). Revista de Geografía Norte Grande, Número 50, pp. 63-85.
González Pizarro, José A

2007 Hablemos de nosotros y de refilón de ellos. Los libros en torno al centenario de Chile y Bolivia. Tercer Milenio, Universidad Católica del Norte, número 14, pp. 64-71.

González Pizarro, José A.

2008 La emigración boliviana en la precordillera de la región de Antofagasta: 1910-1930. Redes sociales y estudio de casos. Revista de Ciencias Sociales, Universidad Arturo Prat, Número 21, pp. 61-85.

González Pizarro, José A.

2009 La literatura de ensayo y las imágenes nacionales de Chile y Bolivia a comienzos del siglo XX. Revista Universum, Universidad de Talca, Número 24, vol. 1, I Semestre, pp. 82-109.

González Pizarro, José A.

2010 La industria minera de Antofagasta y la inmigración boliviana durante el ciclo salitrero. Notas para su estudio. Si Somos Americanos. Revista de Estudios Transfronterizos. Universidad Arturo Prat, volumen X, Número 2, pp. 97-127.

González Pizarro, José A. - Hubert Robinet S.J., André

2013 Luis Silva Lezaeta y el Norte Grande de Chile. Antofagasta, Ediciones Universitarias, Universidad Católica del Norte.

Hajnal, J.

1965 European marriage patterns in perspective. En D. V. Glass y D. E. C. Eversley (Eds), Population in History: essays in Historical Demography. London. Edward Arnold, pp. 101-143.

Iño Daza, Weimar Giovanni

2008 Elites y modernidad en Oruro 1900-1920. La Paz, Museo Nacional de Etnografía y Folklore, RAE Historia, XII, pp. 203-218.

Lora, Guillermo

1969 Historia del Movimiento Obrero Boliviano 1900-1923. La Paz, Los Amigos del Libro.

Manual del Viajero

1910 Baedeker de la República de Chile. Santiago de Chile, Imprenta y Litografía América.

Márquez Ostria, Jorge

2003 Planificación y Ocupación del espacio de Chuquisaca. El carácter histórico de las desigualdades regionales en Bolivia. Fundación Cultural La Plata. Ediciones Agua del Inisterio, Sucre.

Mendieta, Pilar

2006 Oruro ciudad moderna y cosmopolita 1892-1930. En Cajías Magdalena et. al. Ensayos históricos sobre Oruro. La Paz, Colección Cuarto Centenario de la Fundación de Oruro IEB-ASDI, pp. 205-231.

Mesa, José de; Gisbert Teresa, Mesa Gisbert, Carlos D.

1998 Historia de Bolivia. Segunda edición corregida y actualizada, La Paz, Editorial Gisbert. 
Panadés Vargas, Juan Luis-González Pizarro, José Antonio, 1998 Antofagasta, historia de mi ciudad. Antofagasta, Corporación Pro-Antofagasta.

Querejazu Calvo, Roberto

2004 Guano, Salitre, Sangre. Historia de la guerra del Pacífico (La Participación de Bolivia). La Paz, Librería Editorial "G.U.M", tercera edición.

Rodríguez Leyton, Nivardo

2007 Discurso y cultura urbana libertaria en la primera mitad del siglo XX. El discurso anarquista-individualista en el semanario Arte y trabajo (ciudad de Cochabamba 1921-1934), pp. 217-296. En Rosario Rodríguez MárquezMarcelo Villena lvarado (Coordinadores), El espacio urbano andino: escenario de reversiones y reinversiones del orden simbólico colonial. Estudios Bolivianos 13. Universidad Mayor de San Andrés, Instituto de Estudios Bolivianos.

Rojas Delgado, Matías

2012 [1883] El desierto de Atacama y el territorio reivindicado. Santiago de Chile, Biblioteca Nacional, Pontificia Universidad Católica de Chile, Cámara Chilena de la Construcción.

Rowland, R.

1988 Sistemas matrimoniales en la Península Ibérica (siglos XVI-XIX). una perspectiva regional, En Pérez Moreda, V y Reher D (Eds), Demografía Histórica en España. Madrid, Ediciones El Arquero, pp. 72-137.

Salazar A. Luisa-Adela Tisnes

2013 Soltería definitiva en el Río de la Plata. Cambio social y nuevas prácticas en etapas de la familia en crisis, del siglo XVIII a la actualidad. X Congreso de la Asociación de Demografía Histórica, Albaceta, España, 18-21 de junio.
Sanjurjo R., Pilar

2005 Las pautas de nupcialidad de la población inmigrante en España: el reto del intercambio cultural. Cuadernos Geográficos, 36 (1), pp. 65-77.

Sennett, Richard

2002 El declive del hombre público. Ediciones Península, Barcelona.

Schutz, Alfred

1974 Estudios sobre teoría social. Buenos Aires, Amorrortu editores.

Todaro, Michael

1969 A model of labor migration and urban unemployment in less-developed countries. American Economic Review 59: $138-148$

Valdés, Ximena

2007 Notas sobre la metamorfosis de la familia en Chile. En Reunión de Especialistas Futuro de las familias y desafíos para las políticas públicas. Santiago de Chile, Cepal-Unfpa, pp. 2-13.

Valencia Vega, Alipio

1982 Geopolítica del litoral boliviano. La Paz, Librería Editorial Juventud.

\section{Fuentes primarias}

Archivo Histórico de Extranjería del Servicio de Registro Civil e Identificaciones, Universidad Católica del Norte: Bolivia, Cajas 46, 48, 49, 52, 53, 54, 55, 56, 57, 58, 59, $62,63,65,66$.

Servicio del Registro Civil e Identificación de Antofagasta: Libros de Matrimonios: 1885-1930.

\section{Notas}

1 La sigla AHE alude al Archivo Histórico de Extranjería del Servicio del Registro Civil e Identificación de Antofagasta, correspondiente a Bolivia. El primer número, refiere de la Caja y P alude al Prontuario. 